OPEN ACCESS

Edited by:

Jacqueline Batley,

University of Western Australia,

Australia

Reviewed by:

Sukhwinder Singh,

International Maize and Wheat

Improvement Center, Mexico

Junhua $L i$,

Henan Normal University, China

*Correspondence:

Michał T. Kwiatek

mkwi@igr.poznan.pl

Specialty section:

This article was submitted to

Crop Science and Horticulture,

a section of the journal

Frontiers in Plant Science

Received: 23 March 2017

Accepted: 15 June 2017

Published: 28 June 2017

Citation:

Majka M, Kwiatek MT, Majka J and Wiśniewska H (2017) Aegilops tauschii Accessions with Geographically Diverse Origin Show

Differences in Chromosome

Organization and Polymorphism of Molecular Markers Linked to Leaf Rust and Powdery Mildew Resistance

Genes. Front. Plant Sci. 8:1149. doi: 10.3389/fp/s.2017.01149

\section{Aegilops tauschii Accessions with Geographically Diverse Origin Show Differences in Chromosome Organization and Polymorphism of Molecular Markers Linked to Leaf Rust and Powdery Mildew Resistance Genes}

\author{
Maciej Majka ${ }^{1}$, Michał T. Kwiatek ${ }^{1 *}$, Joanna Majka ${ }^{2}$ and Halina Wiśniewska ${ }^{1}$ \\ ${ }^{1}$ Cereal Genomics Team, Department of Genomics, Institute of Plant Genetics, Polish Academy of Sciences, Poznan,, \\ Poland, ${ }^{2}$ Plant Molecular Physiology and Cytogenetics Team, Department of Environmental Stress Biology, Institute of Plant \\ Genetics, Polish Academy of Sciences, Poznań, Poland
}

Aegilops tauschii $(2 \mathrm{n}=2 \mathrm{x}=14)$ is a diploid wild species which is reported as a donor of the D-genome of cultivated bread wheat. The main goal of this study was to examine the differences and similarities in chromosomes organization among accessions of Ae. tauschii with geographically diversed origin, which is believed as a potential source of genes, especially determining resistance to fungal diseases (i.e., leaf rust and powdery mildew) for breeding of cereals. We established and compared the fluorescence in situ hybridization patterns of 21 accessions of Ae. tauschii using various repetitive sequences mainly from the BAC library of wheat cultivar Chinese Spring. Results obtained for Ae. tauschii chromosomes revealed many similarities between analyzed accessions, however, some hybridization patterns were specific for accessions, which become from cognate regions of the World. The most noticeable differences were observed for accessions from China which were characterized by presence of distinct signals of pTa-535 in the interstitial region of chromosome 3D, less intensity of pTa-86 signals in chromosome 2D, as well as lack of additional signals of pTa-86 in chromosomes 1D, 5D, or 6D. Ae. tauschii of Chinese origin appeared homogeneous and separate from landraces that originated in western Asia. Ae. tauschii chromosomes showed similar hybridization patterns to wheat D-genome chromosomes, but some differences were also observed among both species. What is more, we identified reciprocal translocation between short arm of chromosome 1D and long arm of chromosome 7D in accession with Iranian origin. High polymorphism between analyzed accessions and extensive allelic variation were revealed using molecular markers associated with resistance genes. Majority of the markers localized in chromosomes $1 \mathrm{D}$ and 2D showed the diversity of banding patterns between accessions. Obtained results imply, that there is a moderate or high level of polymorphism in the genome 
of Ae. tauschii determined by a geographical origin, which we proved by cytogenetic and molecular markers analysis. Therefore, selected accessions might constitute an accessible source of variation for improvement of Triticeae species like wheat and triticale.

Keywords: Aegilops tauschii, in situ hybridization, leaf rust, markers-assisted selection, polymorphism, powdery mildew

\section{INTRODUCTION}

Aegilops tauschii Coss. $(2 \mathrm{n}=2 \mathrm{x}=14)$ is a diploid wild species which is reported as a donor of the D-genome of cultivated bread wheat - Triticum aestivum L. (Kihara, 1944; McFadden and Sears, 1946). What is more, D-genome is also a part of several tetraploid (i.e., Ae. cylindrica Host and Ae. ventricosa Tausch.) and hexaploid [i.e., Ae. juvenalis (Thell.) Eig and Ae. vavilovii (Zhuk.)] Chennav. species of the genus Aegilops.

Among Aegilops species, Ae. tauschii has the widest geographic distribution, from Turkey on the West to Afghanistan and central Asia in the East, and thus adapted to diversified environmental conditions (Ogbonnaya et al., 2005; Kalia et al., 2016). Ae. tauschii encompasses two subspecies - Ae. tauschii Coss. subsp. strangulata (Eig) Tzvel. and Ae. tauschii subsp. Tauschii (Kalia et al., 2016). Subspecies strangulata is distributed from Transcaucasian region (Armenia, Azerbaijan) to the southeastern Caspian Sea region in Iran, whereas subspecies tauschii is native to the southwestern Caspian Iran and Afghanistan (Kihara et al., 1965; Ogbonnaya et al., 2005; Wang et al., 2013; Kalia et al., 2016). According to previous reports, it is assumed that Ae. tauschii ssp. strangulata is the ancestor of the wheat D-genome (Wang et al., 2013).

Recently, progressive genetic erosion and increasing number of races of pathogens destructive for cereals were observed. Hence, there is need to find new sources of variation for breeding of cereals. Ae. tauschii is an excellent source of novel genes to various biotic and abiotic stresses (Valkoun et al., 1985; Gill et al., 1986; Cox et al., 1992; Assefa and Fehrmann, 2004). Close evolutionary relationship, a variety of genes and relatively easy crossability make this species especially interesting for improvement of cultivated Triticeae species like wheat and triticale (Ogbonnaya et al., 2005). Considering breeding of cereals, one of the main goals is to transfer genes determining resistance to fungal diseases like leaf rust and powdery mildew from wild relatives into cultivated varieties (Gill et al., 1983, 1986; Dhaliwal et al., 1991).

Leaf rust, caused by Puccinia triticina Eriks., occurs on leaves and is one of the most destructive diseases of wheat in the world, because of the ability of the pathogen to adapt to diverse climatic conditions (Kolmer, 1996; Chen et al., 2013). It occurs regularly in the regions with humid and warm environmental conditions like continental Europe with a temperate climate and leads up to $30 \%$ of yield losses (Roelfs et al., 1992). It was reported that genetic engineering of host resistance is both profitable and safe for environment approach to control leaf rust (Assefa and Fehrmann, 2000; Kalia et al., 2016). According to the literature, Ae. tauschii is a source of four seedling resistance genes [ Lr21
(1D), Lr32 (3D), Lr39 (2D), Lr42 (1D)] and one determining adult plant resistance $[\operatorname{Lr} 22 a(2 \mathrm{D})]$.

Powdery mildew, caused by Blumeria graminis f. sp. tritici, is second globally important leaf disease not only in wheat but also in triticale breeding, because populations of the pathogen are very dynamic and continually change their virulence structure. It is very common in Europe, parts of Asia, and the southeastern part of North America, with high rainfalls and maritime or semicontinental climate, where powdery mildew occurs annually and leads to significant yield losses (Wang et al., 2016). So far, the most feasible means of controlling the disease is by host resistance (Bennett, 1984; Wang et al., 2016). Over 70 powdery mildew resistance $(P m)$ alleles at 50 loci have been formally designated (Pm1-Pm54), whereas genes Pm2 (5D), Pm19 (7D), Pm34 (5D), and Pm35 (5D) were originated from Ae. tauschii (Cowger et al., 2012; Wang et al., 2016). What is more, Ae. tauschii might constitute also a valuable source of Pm43 gene (Majka et al., 2016), which was previously mapped on chromosome $2 \mathrm{D}$ of this species by Jia et al. (2013).

So far, many efforts have been undertaken to characterize genetically diverse accessions of Ae. tauschii using SSR markers also in terms of disease resistance (Naghavi et al., 2009; Chhuneja et al., 2010). Despite a large number of analyzed accessions (13 and 85 , respectively) and SSR markers (21 and 51, respectively) used in this study, none of the markers were assigned to resistance genes. Singh et al. (2012) evaluated 63 accessions of Ae. tauschii for marker-trait association using 35 SSR markers, and identified six SSR markers significantly associated with leaf rust resistance genes (Xcfd19, Xgdm35, Xgwm261, Xgwm515, $X c f d 4$, and $X g w m 645)$. It was reported that using this markers the germplasm collections can be initially screened and characterized to identify candidate genetic stocks and genomic regions (Singh et al., 2012). What is more, some microsatellites markers associated with leaf rust resistance genes localized in D-genome were reported for bread wheat (Huang et al., 2003; Hiebert et al., 2007; Thomas et al., 2010).

Karyotype and C-banding patterns of Ae. tauschii chromosomes were reported by many authors (Chennaveeraiah, 1960; Gill and Kimber, 1974; Iordansky et al., 1978; Teoh and Hutchinson, 1983; Friebe et al., 1992). What is more, Ae. tauschii chromosomes were also examined using in situ hybridization with various probes, like pTa71 (18S-5.8S-26S rDNA), pTa794 (5S rDNA), pAs1 (Afa family) and pSc119.2 (Badaeva et al., 2002; Kwiatek et al., 2013; Molnar et al., 2014). However, in two of this studies only one accession of Ae. tauschii was taken under investigations. So far, only Friebe et al. (1992) and Badaeva et al. (2002) using C-banding technique revealed polymorphism between respectively 15 and 12 accessions of Ae. tauschii with 
a different origin. The number and distribution of repetitive sequences used in previous studies for fluorescent in situ hybridization were not sufficient to cover the whole karyotype of this species. What is more, the number and distribution of rDNA loci in the Triticeae species are reported to be a conservative feature (Badaeva et al., 1996). Because of the great agronomic importance of the D-genome in bread wheat, this genome was well-studied on the cytogenetic level using different probes especially repetitive sequences with oligonucleotides amongst them.

D-genome chromosomes of wheat cultivar Chinese Spring were studied in terms of distribution of synthetic oligonucleotides (2-3 bp repeats) (Cuadrado et al., 2000, 2008). Among 12 analyzed sequences only two allowed to obtain distinctive hybridization signals. (AAG) $)_{5}$ revealed signals in chromosomes $1 \mathrm{D}, 2 \mathrm{D}$ and $7 \mathrm{D},(\mathrm{AGG})_{5}$ single and weak signals in chromosomes $2 \mathrm{D}$, whereas two other sequences $(\mathrm{AC})_{8}$ and $(\mathrm{GCC})_{5}$ revealed dispersed signals scattered along the chromosomes (Cuadrado et al., 2008). Moreover, the presence of weak and single signals of GAA satellite sequence in chromosomes 1D, 2D, and 7D was also reported (Pedersen and Langridge, 1997; Komuro et al., 2013). On the other hand, fluorescence in situ hybridization (FISH) with repetitive sequences from BAC library of wheat (cv. Chinese Spring) revealed the presence of hybridization signals in D-genome and availability of sequences for Ae. tauschii karyotyping.

The main goal of this work was to examine the differences and similarities in chromosomes organization between the accessions of Ae. tauschii with a different origin in order to identify new sources of variation for breeding of Triticeae species especially resistance to fungal diseases. Therefore cytogenetic analyses were supported with molecular markers associated with genes determining resistance to leaf rust and powdery mildew.

\section{MATERIALS AND METHODS}

\section{Plant Material}

The list of all accessions of Ae. tauschii used in this study with their origin is shown in Table 1. The materials were kindly provided by the United States Department of Agriculture, the Agricultural Research Service (Aberdeen, ID, United States), as well as were derived from the collection of the Institute of Plant Genetics, Polish Academy of Sciences (Poznań, Poland). For the molecular markers analysis triticale cv. Bogo, wheat cultivars Chinese Spring, Thatcher and NILs of wheat cv. Thatcher carrying $\operatorname{Lr} 22 a, \operatorname{Lr} 22 b$ and $\operatorname{Lr} 39$ genes, were used as control plants. Wheat cv. Thatcher and NILs of this cultivar were kindly provided by Dr. A. Serfling (Julius Kühn-Institut, Federal Research Centre for Cultivated Plants, Quedlinburg, Germany). All plants were grown in a greenhouse at the Institute of Plant Genetic of the Polish Academy of Sciences.

\section{Chromosome Preparation and Labeling of Probes}

Germination, metaphase accumulation, and fixation procedures were carried out according to Kwiatek et al. (2016a).
TABLE 1 | List of Aegilops tauschii accessions used in the study.

\begin{tabular}{|c|c|c|c|c|}
\hline No. & Genotype & $\begin{array}{l}\text { Accession } \\
\text { number }\end{array}$ & Origin & GenBank* \\
\hline 1 & Tau-1 & PI 486270 & Turkey, Hakkari & USDA-ARS/USA \\
\hline 2 & Tau-2 & PI 486271 & Turkey, Van & USDA-ARS/USA \\
\hline 3 & Tau-3 & PI 486272 & Turkey, Van & USDA-ARS/USA \\
\hline 4 & Tau-4 & PI 486274 & Turkey, Kars & USDA-ARS/USA \\
\hline 5 & Tau-5 & PI 486275 & Turkey, Kars & USDA-ARS/USA \\
\hline 6 & Tau-6 & PI 486276 & Turkey, Kars & USDA-ARS/USA \\
\hline 7 & Tau-7 & PI 486277 & Turkey, Kars & USDA-ARS/USA \\
\hline 8 & Tau-8 & PI 499262 & China, XinJiang & USDA-ARS/USA \\
\hline 9 & Tau-9 & PI 508261 & China, XinJiang & USDA-ARS/USA \\
\hline 10 & Tau-10 & PI 508262 & China, XinJiang & USDA-ARS/USA \\
\hline 11 & Tau-11 & PI 511362 & Pakistan, Baluchistan & USDA-ARS/USA \\
\hline 12 & Tau-12 & PI 511363 & Afghanistan, Faryab & USDA-ARS/USA \\
\hline 13 & Tau-13 & PI 511369 & Iran, Mazandaran & USDA-ARS/USA \\
\hline 14 & Tau-14 & PI 554311 & Turkey, Van & USDA-ARS/USA \\
\hline 15 & Tau-15 & D1 & Unknown & IPG PAS/Poland \\
\hline 16 & Tau-16 & $\mathrm{D} 2$ & Unknown & IPG PAS/Poland \\
\hline 17 & Tau-17 & D15 & Unknown & IPG PAS/Poland \\
\hline 18 & Tau-18 & D17 & Turkey & IPG PAS/Poland \\
\hline 19 & Tau-19 & D27 & Unknown & IPG PAS/Poland \\
\hline 20 & Tau-20 & D51 & Unknown & IPG PAS/Poland \\
\hline 21 & Tau-21 & D98 & Unknown & IPG PAS/Poland \\
\hline
\end{tabular}

*USDA-ARS, United States Department of Agriculture, Agricultural Research Service, Aberdeen, ID, United States. IPG PAS, Institute of Plant Genetics, Polish Academy of Sciences, Poznań, Poland.

The chromosome slides were obtained from root tips with squash method according to Hasterok et al. (2006) with minor modifications. Three root meristems were collected from five plants of each accession. Chromosome preparations were carried out from each of three root meristems. The following five repetitive sequences were used for FISH: pTa-86, pTa-465, pTa-535, pTa-k566, pTa-713, and microsatellite (GAA) 5 . Selected sequences were amplified from the clones derived from BAC library of wheat cv. Chinese Spring reported by Komuro et al. (2013) according to Kwiatek et al. (2016b). After amplification, all products were electrophoresed, stained, visualized and photographed to confirm their length before labeling. All five pTa sequences were labeled with nick translation kits according to the instructions provided by the producers. Probes pTa-535 and pTa-k566 were labeled using tetramethyl-5-dUTP-rhodamine (Roche), pTa-86 was labeled with digoxigenin-11-dUTP (Roche) and pTa-465 and pTa-713 were labeled by Atto647N (Jena BioScience). (GAA) 5 oligoprobe was end-labeled with the enzyme terminal deoxynucleotidyl transferase (TdT) and had digoxigenin-modified nucleotide attached at the $5^{\prime}$ end (Sigma).

\section{Fluorescent In Situ Hybridization}

FISH procedure was performed according to Kwiatek et al. (2016a) with minor modifications. Six probes [pTa-86, pTa-465, pTa-535, pTa-k566, pTa-713, and (GAA $)_{5}$ ] were subjected to in situ hybridization on the same chromosome preparations. In the first FISH trial, pTa-86, pTa-535, pTa-713 probes were applied. The hybridization mixture $(20 \mu \mathrm{l}$ per slide) contained 
$90 \mathrm{ng}$ of each probe in the presence of salmon sperm DNA, 50\% formamide, $2 \times$ SSC, and $10 \%$ dextran sulfate, and was denatured at $70^{\circ} \mathrm{C}$ for $10 \mathrm{~min}$ and stored on ice for $5 \mathrm{~min}$. Denaturation of slides and hybridization mixture was carried out at $70^{\circ} \mathrm{C}$ for $3 \mathrm{~min}$ and hybridization was performed at $37^{\circ} \mathrm{C}$ for $20 \mathrm{~h}$. The probes labeled with digoxigenin were detected using antidigoxigenin-fluorescein antibody (Roche). After acquisition of sites obtained for the first FISH trial, the slides were washed according to Heslop-Harrison (2000) with minor modifications $\left(2 \mathrm{~min} \times 15 \mathrm{~min}\right.$ in $4 \times \mathrm{SSC}$ Tween in $37^{\circ} \mathrm{C}$ and $1 \mathrm{~min} \times 5 \mathrm{~min}$ in $2 \times$ SSC, at room temperature). Second FISH trial with pTa-k566, pTa-465 and (GAA) 5 probes was made with the same conditions after reprobing. Each set of probes was tested on chromosomes of T. aestivum Chinese Spring, as a control. 10 metaphases per slide were analyzed and documented with an Olympus BX 61 automatic epifluorescence microscope supplied with Olympus XM10 CCD camera. Image processing was carried out using the Olympus Cell-F (version 3.1; Olympus Soft Imaging Solutions $\mathrm{GmbH}$ : Münster, Germany) imaging software and PaintShop ProX5 software (version 15.0.0.183; Corel Corporation, Ottawa, ON, Canada).

\section{PCR Amplification of Molecular Markers}

Total genomic DNA was isolated from 2-weeks-old leaves of individual accessions of Ae. tauschii, triticale cv. Bogo, wheat cultivars Chinese Spring, Thatcher and NILs of this cultivar, using GeneMATRIX Plant and Funghi DNA Purification Kit (EURx, Ltd) according to the manufacturer instruction. Analyses were performed with $25 \mu \mathrm{l}$ mixture according to the procedure supplied to the 2x PCR TaqNovaHS PCR Master Mix (Blirt). PCR reaction mix consist of Master mix (containing hot start polymerase), $10 \mu \mathrm{M}$ of each forward and reverse primer, DNA template and PCR-grade water. PCR reactions were carried out according to producer protocol with appropriate annealing temperature $\left(52-60^{\circ} \mathrm{C}\right)$ estimated for every molecular marker (Table 2). Amplification products were separate in agarose gel (Sigma), stained, visualized, and photographed according to Kwiatek et al. (2016b).

\section{RESULTS}

\section{Distribution of Highly Repetitive DNA Sequences on Chromosomes}

The FISH experiments were carried out on 21 accessions of Ae. tauschii in order to detect chromosome polymorphisms. To identify all chromosomes and genetic variation between analyzed accessions, two sets of probes were subjected to in situ hybridization: (1) pTa-86 + pTa-535 + pTa-713 (Figure 1) and (2) pTa-465 + pTa-k566 + (GAA) 5 (Figure 2). The karyotypes were analyzed and obtained hybridization patterns were compared with that obtained for D-genome by Komuro et al. (2013). Most of the Ae. tauschii chromosomes showed similar hybridization patterns, but some differences were observed among accessions of different origin.

\section{Sequence pTa-535}

Hybridization of Ae. tauschii chromosomes with pTa-535 revealed signals in all chromosomes, localized mainly in the telomeric regions. The hybridization pattern was similar in all accessions, however in chromosomes 3D (Tau-8, Tau-9, Tau-10) and 5D (Tau-4, Tau-17, Tau-18) the size of the sites located in the middle of the long arm was variable (Figure 1). On the basis of pTa-535 distribution in Tau-13 a reciprocal translocation between short arm of chromosome 1D and long arm of chromosome 7D was observed (Figure 3).

\section{Sequence pTa-86}

Patterns of $\mathrm{pTa}-86$ probe were the most variable between analyzed accessions of Ae. tauschii. Intraspecific differences were found for chromosomes 1D, 2D, 4D, 5D, and 6D. The hybridization signal was observed in short arm of chromosome 1D only in Tau-15, Tau-16, and Tau-17 (Figure 1). For most of the accessions, signals observed in the terminal region of chromosome $2 \mathrm{D}$ were similar, however, these ones varied in Tau-1 more distinct signals (Figure 1); Tau-8, Tau-9, Tau-10 (less distinct signals), as well as Tau-16 and Tau-17 with the absence of hybridization signals (Figure 1). On chromosome 4D, signals of pTa-86

TABLE 2 | Sequences and annealing temperatures for molecular markers associated with resistance genes used in the study.

\begin{tabular}{|c|c|c|c|}
\hline Marker name (gene) & Primer sequence $\left(5^{\prime}-3^{\prime}\right)$ & Annealing temperature $\left({ }^{\circ} \mathrm{C}\right)$ & Reference \\
\hline \multirow[t]{2}{*}{ Xcfd19 (Lr32) } & TACGCAGGTITGCTGCTT CT & 59 & Guyomarc'h et al., 2002 \\
\hline & GGAGTTCACAAGCATGGGTT & & \\
\hline \multirow[t]{2}{*}{ Xksu-D14 (Lr32) } & CGCTITACCGAGATTGGTC & 59 & Boyko et al., 1999 \\
\hline & CCAAAGAGCATCCATGGTGT & & \\
\hline \multirow[t]{2}{*}{ Xgwm296 (Lr22a, Lr39) } & AАTTCAACCTACCAATCTCTG & 52 & Roder et al., 1998 \\
\hline & GCCTAATAAACTGAAAACGAG & & \\
\hline \multirow[t]{2}{*}{ Xgdm35 (Lr22a, Lr39) } & CCTGCTCTGCCCTAGATACG & 60 & Pestsova et al., 2000 \\
\hline & ATGTGAATGTGATGCATGCA & & \\
\hline \multirow[t]{2}{*}{ Xcfd4 (Lr32) } & TGCTCCGTCTCCGAGTAGAT & 59 & Guyomarc'h et al., 2002 \\
\hline & GGGAAGGAGAGATGGGAAAC & & \\
\hline \multirow[t]{2}{*}{ Xbarc135 (Lr32) } & ATCGCCATCTCCTCTACCA & 58 & Song et al., 2005 \\
\hline & GCGAACCCATGTGCTAAGT & & \\
\hline \multirow[t]{2}{*}{ Xgwm539 (Pm43 homolog) } & CTGCTCTAAGATTCATGCAACC & 58 & Roder et al., 1998 \\
\hline & GAGGCTTGTGCCCTCTGTAG & & \\
\hline
\end{tabular}




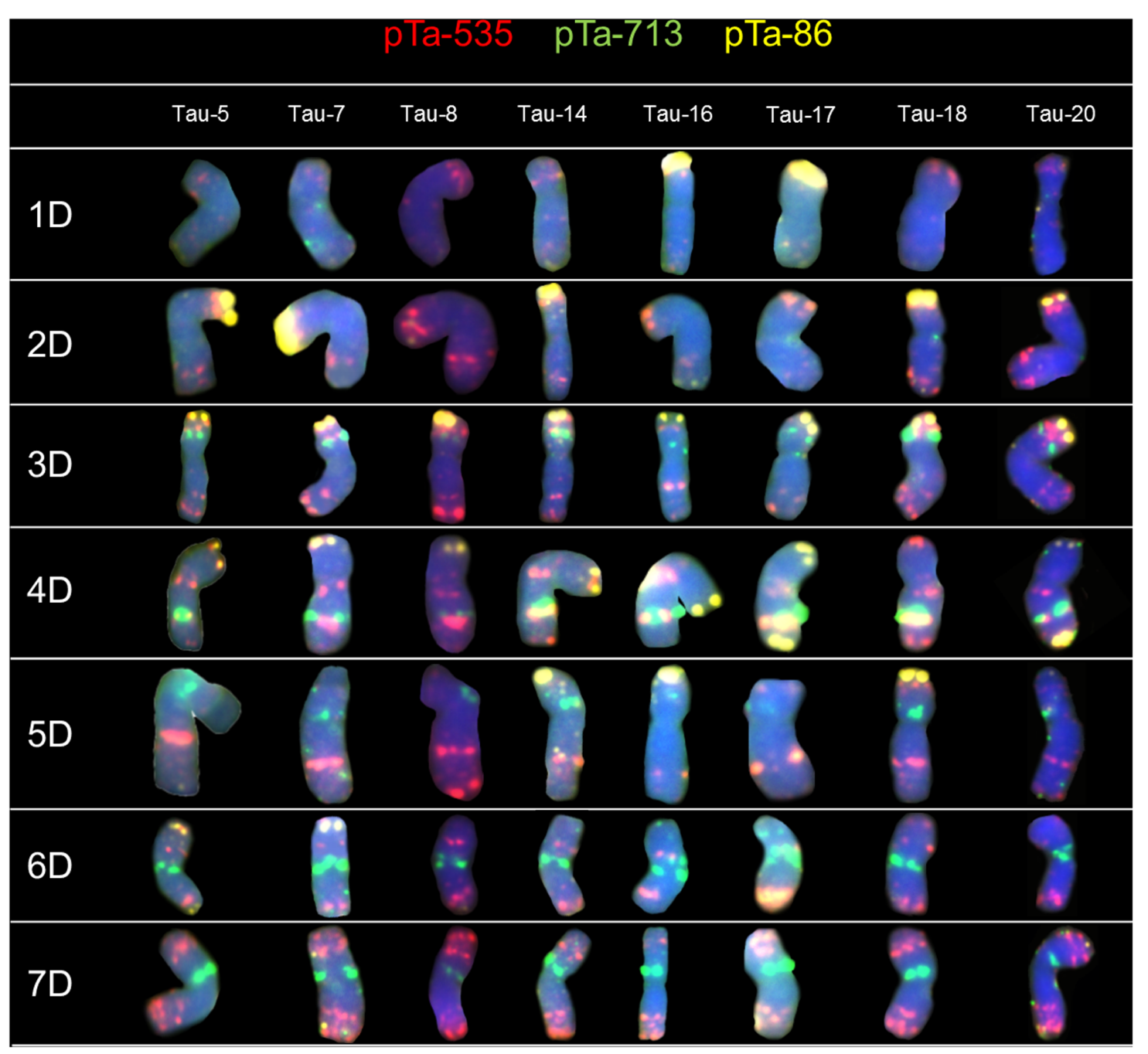

FIGURE 1 | Karyograms of Tau-5, Tau-7, Tau-8, Tau-14, Tau-16, Tau-17, Tau-18, and Tau-20 after FISH with pTa-535 (red), pTa-86 (yellow), and pTa-713 (green) probes.

were detected mainly in the terminal part of short arm (4DS), though some accessions (Tau-17, Tau-20, Tau-21) possessed additional signals in the terminal region of long arm (4DL) (Figure 1). In two accessions Tau-3 and Tau-18 we did not reveal any signals for this probe in chromosome 4D (Figure 1). Moreover, the pTa- 86 signals appeared in the terminal region of short arm of 5D chromosomes of Tau-2, Tau-3, Tau-4, Tau-6, Tau-14, Tau-15, Tau-16, Tau-18, and Tau-19 (Figure 1). What is more, this probe hybridized to the telomeric regions of chromosome 6D, concerning short arm of chromosomes of Tau- 4 and Tau-7; long arm of Tau-2 and Tau-14 and both arms of Tau-5 (Figure 1).

\section{Sequence pTa-713}

Sites of pTa-713 probe were present in several chromosomes of Ae. tauschii. The most distinct signals were observed in the interstitial regions of chromosomes 3D, 4D and 5D, as well as in the pericentromeric regions of chromosomes
6D and 7D (Figure 1). Intraspecific variation in signal localization and intensity between accessions was not observed.

\section{Sequence pTa-k566}

Fluorescence in situ hybridization with pTa-k566 resulted in clear, distinct signals localized in the interstitial regions of chromosome 1D in both arms, chromosome 2D (both arms), chromosomes 5D and 6D (short and long arm, respectively), as well as in short arm of chromosome 7D (Figure 2). The hybridization pattern was similar in all accessions. Some differences were observed between analyzed accessions in the distribution of pTa-k566 probe in chromosome 1D. In accession Tau-16 one additional site of hybridization in the short arm of chromosome 3D was identified (Figure 2). The distribution pattern of pTa-k566 clone allows to confirm a reciprocal translocation between short arm of chromosome 1D and long arm of chromosome 7D in Tau-13 (Figure 3). 

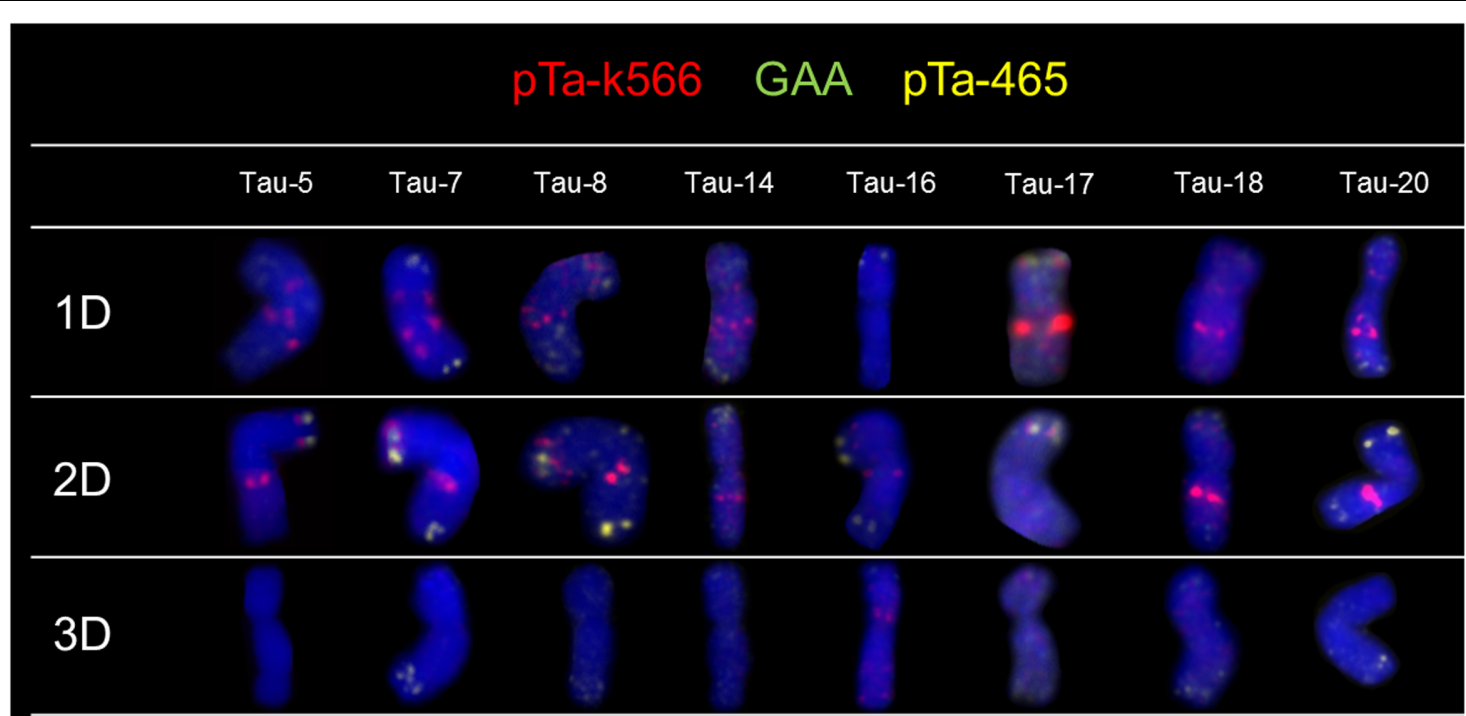

4D

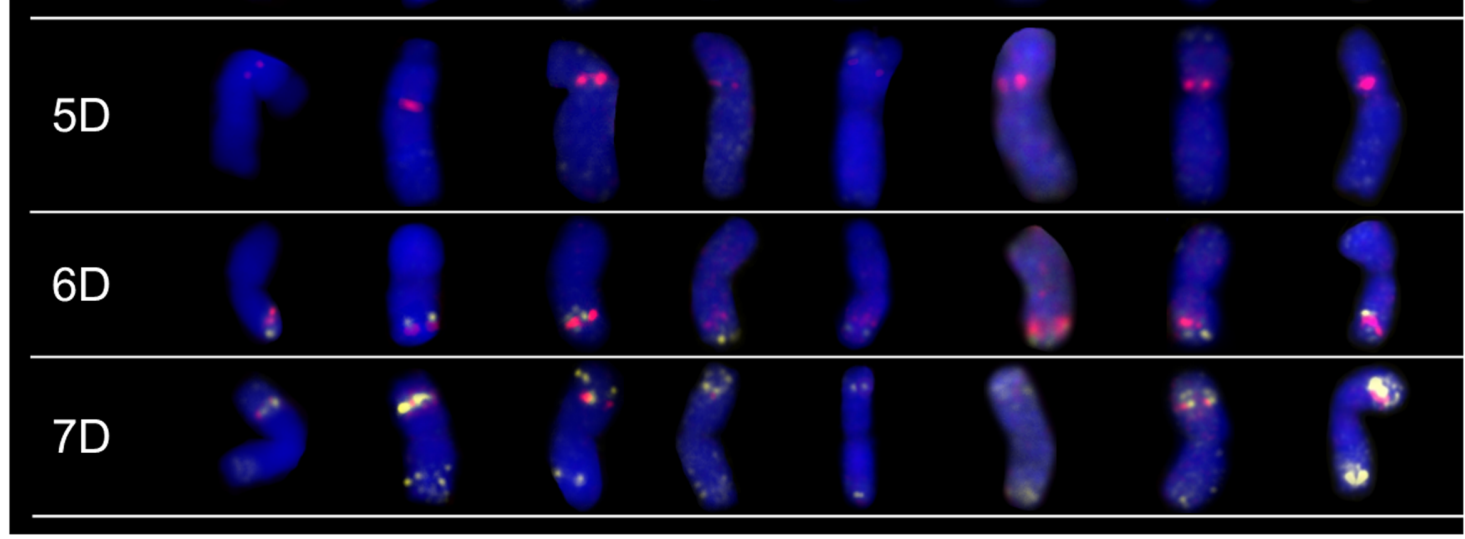

FIGURE 2 | Karyograms of Tau-5, Tau-7, Tau-8, Tau-14, Tau-16, Tau-17, Tau-18, and Tau-20 after FISH with pTa-k566 (red), pTa-465 (yellow), and (GAA)5 (green) probes.

\section{Sequence pTa-465}

pTa-465 probe hybridized mainly to the distal regions of chromosomes 1D, 2D, 3D, 6D, and 7D (Figure 2). The most distinct signals were observed in terminal regions of both arms of chromosome 7D (Figure 2). The hybridization pattern was similar in all accessions. However, in Tau-14, Tau-15, Tau-18, Tau-19 and Tau-21, additional signals in the terminal region of the short arm of chromosome $6 \mathrm{D}$, where this probe co-localized with pTa-k566 clone, were observed (Figure 2).

\section{Sequence GAA}

We have not revealed any GAA signals in chromosomes of all analyzed accessions of Ae. tauschii (Figure 2). All experiments with GAA motif as a probe, were also carried out on chromosomes of T. aestivum cv. Chinese Spring, as a positive control.

\section{Analysis of Molecular Markers Related to Ae. tauschii Leaf Rust Resistance Genes}

Six molecular markers associated with leaf rust resistance genes [Xcfd19 and XksuD14 (Lr32, 1D); Xgwm296 and Xgdm35 (Lr22a, Lr39, 2D); Xcfd4 and Xbarc135 (3D)] and one marker linked with powdery mildew [Xgwm539 (Pm43 homolog, 2D)] resistance were used. The results showed the high polymorphism between all analyzed accessions of Ae. tauschii.

Amplification of XksuD14 marker resulted in $1.36 \mathrm{~kb}$ product indicating the presence of $L r 32$ gene and was observed in all of Ae. tauschii accessions with expect of Tau-11, Tau-13, Tau-20 and Tau-21. What is more, $1.2 \mathrm{~kb}$ band was observed in Tau-1-Tau-9, Tau-14, Tau-15, Tau-17, and Tau-18. Similar banding patterns were obtained for Tau-10, Tau-11, Tau-12, Tau-13, Tau-20 and Tau-21, where a strong band of about $800 \mathrm{bp}$ size was identified. This result was in accordance with similarities 


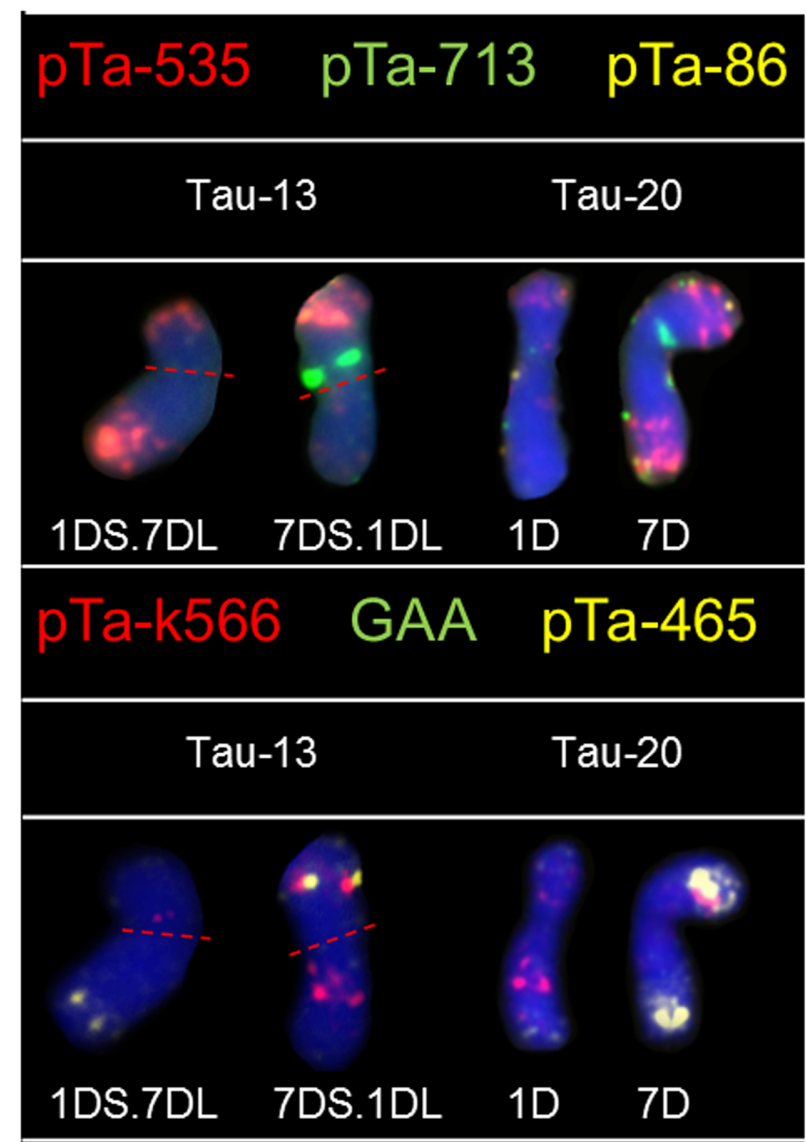

FIGURE 3 | Karyograms of Tau-13 and Tau-20 after FISH with pTa-535 (red) pTa-86 (yellow), and pTa-713 (green) probes and reprobing with pTa-k566 (red), pTa-465 (yellow), and (GAA) 5 (green) probes. Dotted lines indicate translocation breakpoints in centromeres.

observed for the same accessions for Xcfd19 marker, which is localized nearby Lr21 gene. Results obtained for Xgdm35 marker revealed that allele determining resistance $(180 \mathrm{bp})$ was present in Tau-4, Tau-5, Tau-6, Tau-10, Tau-11, Tau-13, Tau-19, Tau-20, and Tau-21 (Figure 4). It is worth to mention, that the size of the bands differs between accessions of Ae. tauschii and NILs of T. aestivum cv. Thatcher with Lr39, however, one accession (Tau-18) had banding pattern similar to those obtained for Tc-Lr39 (Figure 4). Presence of another resistant gene Lr22, localized in chromosome 2D was determined with Xgwm296 marker. The banding pattern specific for resistance allele Lr22a was present in most of the analyzed accessions with expect of Tau-3 and Tau-16 which pattern was similar to those obtained for wheat cultivar Thatcher. In case of using Xbarc135 and Xcfd4 markers associated with Lr32 gene, the high polymorphism of obtained banding patterns was revealed between all analyzed $A e$. tauschii accessions. Amplification of Xgwm539 marker resulted in a product of $150 \mathrm{bp}$ size and was present in most of the analyzed accessions. What is more, three of them: Tau-15, Tau-16, and Tau-17 had banding pattern similar to wheat cultivars Chinese Spring and Thatcher.
It is worth pointing out that in case of all six markers linked to leaf rust resistance, Tau-10 had different organization of those loci in comparison with two other accessions of Chinese origin: Tau-8 and Tau-9. What is more, selected molecular markers revealed polymorphism within Turkish accessions. The most distinctive differences were observed in the comparison of banding patterns obtained for Xbarc135, Xgdm35, and Xcfd19 markers. The differences and similarities in genome organization were in accordance with the origin of particular accessions of Ae. tauschii.

\section{DISCUSSION}

Komuro et al. (2013) reported that combination of pTa$86+$ pTa-535 + pTa-713 probes allows to discriminate all D-genome chromosomes of wheat without ambiguity including their orientation. What is more, by overlaying pTa-465, pTa-k566 and GAA FISH signals, wheat D-genome chromosomes were highly decorated. The main goal of this study was to examine the differences and similarities in chromosomes organization among accessions of Ae. tauschii with a different origin, which is believed as a potential source of genes especially determining resistance to fungal diseases (i.e., leaf rust) that could be used in wheat and triticale breeding.

Results obtained for Ae. tauschii chromosomes revealed many similarities between analyzed accessions, however, some hybridization patterns were specific for accessions which become from cognate regions of the World. The most noticeable differences were observed for accessions from China which were characterized by presence of distinct signals of pTa-535 in the interstitial region of chromosome $3 \mathrm{D}$, less intensity of pTa-86 signals in chromosome $2 \mathrm{D}$, as well as lack of additional signals of pTa-86 in chromosomes $1 \mathrm{D}, 5 \mathrm{D}$, or $6 \mathrm{D}$ (Figure 1). These results were in compliance with results of Wang et al. (2013) who reported that landraces of Ae. tauschii of Chinese region and other wheats of the Far Eastern origin appeared homogeneous and separate from landraces that originated in western Asia.

Chromosomes $1 \mathrm{D}$ and $2 \mathrm{D}$ of Ae. tauschii are of great importance because on this chromosomes many resistance genes have been mapped (Gill et al., 2008; Majka et al., 2016). In wheat, those chromosomes were found to be highly polymorphic, whereas in all wheat D-genome chromosomes most genetic diversity was localized in the terminal parts of chromosomes and was correlated with high recombination rates (Akhunov et al., 2010; Wang et al., 2013). It was assumed that wheat polymorphisms must have been introgressed into wheat from Ae. tauschii (Wang et al., 2013). The high content of genes is directly proportional to the low content of repetitive sequences along the entirety of chromosomes $1 \mathrm{D}$ and $2 \mathrm{D}$ what was in accordance with the scarcity of hybridization sites of $\mathrm{pTa}$ probes which are repetitive sequences. Especially terminal region of the short arm of chromosome 2D is characterized by high recombination rate. This region was reported to be exposed to chromosome rearrangements, though such places in the genome may constitute a hot spots (Luo et al., 2009, 2013; Majka et al., 


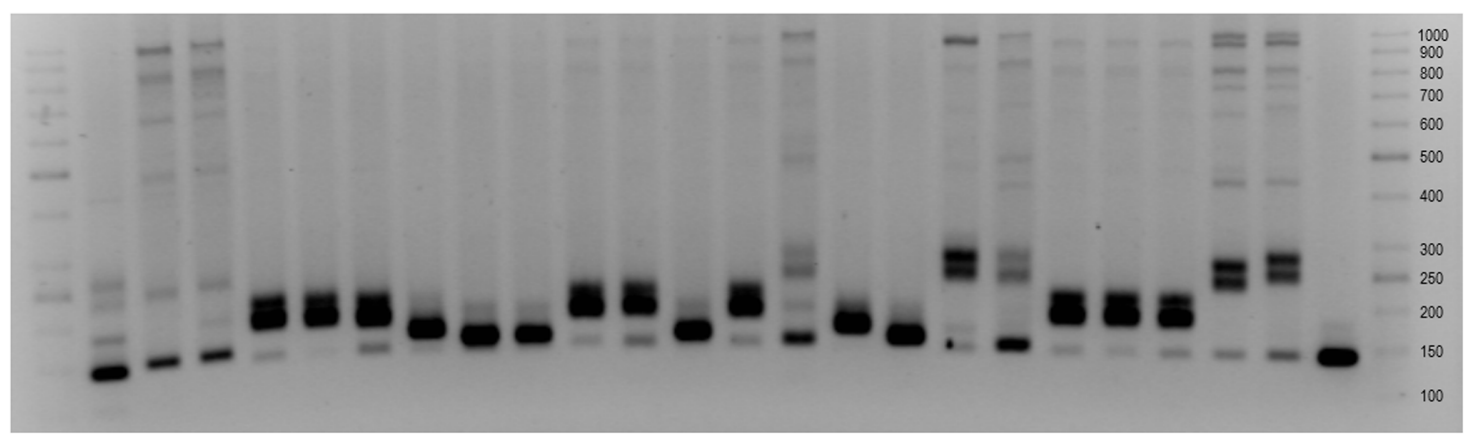

FIGURE 4 | Xgdm35 marker associated with Lr39 gene (1) DNA Ladder 50 bp, (2-22) Tau-1-Tau-21, (23) Thatcher, (24) Thatcher-Lr39, (25) Bogo (26) DNA Ladder $50 \mathrm{bp}$.

2016). Tau-16 and Tau-17 are the only accessions that lacks signals of the pTa-86 signals in chromosome 2D (Figure 1). What is more, results obtained for the rest of Ae. tauschii chromosomes confirm the patterns of genetic diversity among $\mathrm{D}$-genome chromosomes and arms of wheat where diversity is high in terminal region of the long arm of chromosome $4 \mathrm{D}$, and both terminal regions of chromosome 6D. In the contrary, very low levels of diversity were reported for the whole chromosomes $3 \mathrm{D}$ and $5 \mathrm{D}$, three-quarters of chromosome $4 \mathrm{D}$, and terminal regions of 6D (Akhunov et al., 2010). Friebe et al. (1992) reported a large amount of polymorphic variation in C-bands size, as well as in the intra-chromosomal distribution pattern of these bands between different accessions of Ae. tauschii. It is known, that $\mathrm{C}$-banded regions are composed of highly repetitive DNA sequences and the location of hybridization sites in this work are similar to the C-banding distribution in chromosomes of Ae. tauschii reported by Friebe et al. (1992). Moreover, it was shown, that Ae. tauschii TA 2462 (origin - Mazandaran province, Iran) carry a reciprocal translocation T1DS.7DL and T7DS.1DL basing on C-banding and hybridization patterns of pAs1 probe (Friebe et al., 1992). What is more, Hohmann and Lagudah (1993) using C-banding technique reported the same reciprocal interchange between chromosomes, with the breakpoints located in the centromeric region of Ae. tauschii accession AUS 18902 with Iranian origin. The same translocation was present in Tau-13 (this work; origin - Mazandaran province, Iran), what indicates a common origin of all accessions (Figure 3).

In this study Ae. tauschii chromosomes showed similar hybridization patterns to wheat D-genome chromosomes, however, some differences were also observed among both species. It is worth to mention, that combination of pTa$86+$ pTa-535 + pTa-713 probes allows to discriminate all Ae. tauschii chromosomes and their orientation according to Komuro et al. (2013). Terminal parts of chromosomes 1DL, 5DS, and 6DS carried less distinct pTa-535 signals in comparison to wheat cv. Chinese Spring. The crucial differences concern the distribution and intensity of $\mathrm{pTa}-86$ probe. The typical pattern for this repetitive sequence revealed signals in terminal regions of chromosomes (short arms) 2D, 3D, and 4D
(Figure 1). What is more, in about $43 \%$ of analyzed accessions strong hybridization signals in short arm of chromosome 5D, were identified (Figure 1). In addition, no differences were observed for pTa-713 probe. The hybridization patterns of all probes established on Tau-13 chromosomes were similar to those observed in wheat Chinese Spring. This accession was collected in Mazandaran province in Iran, what is in relevance with the results obtained by Wang et al. (2013) who report that southwestern and southern Caspian accessions of Ae. tauschii appears to be the main source of the wheat D-genome.

pTa-86 clone is a homolog of pSc119.2 sequence which was derived from S. cereale (Bedbrook et al., 1980; Komuro et al., 2013). The typical hybridization pattern obtained for Ae. tauschii chromosomes revealed six strong hybridization signals in terminal parts of chromosomes 2D, 3D, and 4D (short arms) (Figure 1). That results were in coincidence with hybridization pattern of pSc119.2 obtained for Ae. tauschii accession MvGB605 by Molnar et al. (2014) and for accession Tau-20 by Kwiatek et al. (2013), where additional signals in terminal region of chromosome 4DL were also observed. However, both papers did not reveal any distinct signals of $\mathrm{pSc1} 19.2$ in chromosomes $1 \mathrm{D}, 5 \mathrm{D}$ and $6 \mathrm{D}$, what confirms that this hybridization pattern is specific only for some accessions with a different origin. Majka et al. (2017), hybridized gDNA of rye to chromosomes of Ae. tauschii (Tau-20) what reveals chromosome labeling and six terminal signals in chromosomes without $5 \mathrm{~S}$ and 35 SrDNA loci (1D and 5D). In this paper we also observed six distinct hybridization signals obtained for pTa-86 probe, what is consistent with GISH results and confirms homology of pTa-86 with pSc119.2 sequence derived from $S$. cereale (Figure 1).

High polymorphism between analyzed accessions and extensive allelic variation were revealed using molecular markers associated with resistance genes. In case of most of the markers localized in chromosomes $1 \mathrm{D}$ and $2 \mathrm{D}$, the diversity of banding patterns was high. Additionally, results obtained for markers located in the distal part of the short arm of chromosome 3D also revealed the high diversity of obtained banding patterns. What is more, the differences in number and size of the bands 
were observed even between accessions with close origin. It should be mention that most of the analyzed molecular markers, thus resistance genes, were mapped to the distal parts of D-genome chromosomes (Somers et al., 2004; Liu et al., 2014). Only two of them Xgwm296 and Xgwm539 were mapped to the interstitial parts of chromosomes, but the polymorphism of obtained banding patterns was low. That confirms the high polymorphism of chromosomes $1 \mathrm{D}$ and $2 \mathrm{D}$, as well as high recombination rates at the ends of D-genome chromosomes (Akhunov et al., 2010; Luo et al., 2013). What is more, Naghavi et al. (2009) using SSR markers reported that genetic variability in the genome of Ae. tauschii were higher than in D-genome of bread wheat. Therefore, this wild species might constitute a source of agronomically important genes that could be transferred into wheat germplasm (Naghavi et al., 2009). Singh et al. (2012) reported that only one of the known, major leaf rust resistance genes Lr39 was declared to be associated with marker $X g d m 35$, through the conservative test. They declared that $180 \mathrm{bp}$ product obtained for Ae. tauschii is directly related to the resistance. What is more, Wiśniewska et al. (2007) obtained 250 bp product for wheat cultivar Thatcher, whereas Sun et al. (2009) show that Xgdm35 amplified polymorphic products (229-265 bp in range) in diverse wheat germplasm (239 bp in wheat cultivar Chinese Spring). This reports were in compliance with results obtained in this study and indicates that Tau-4, Tau-5, Tau-6, Tau-10, Tau-11, Tau-13, Tau-19, Tau-20, and Tau-21 can consist a source of leaf rust resistance, whereas Tau-18 has similar organization of Xgdm35 locus in comparison to wheat cultivar Thatcher-Lr39 (Figure 4).

\section{REFERENCES}

Akhunov, E. D., Akhunova, A. R., Anderson, O. D., Anderson, J. A., Blake, N., Clegg, M. T., et al. (2010). Nucleotide diversity maps reveal variation in diversity among wheat genomes and chromosomes. BMC Genomics 11:702. doi: 10.1186/ 1471-2164-11-702

Assefa, S., and Fehrmann, H. (2000). Resistance to wheat leaf rust in Aegilops tauschii Coss. and inheritance of resistance in hexaploid wheat. Genet. Resour. Crop Evol. 47, 135-140. doi: 10.1023/A:1008770226330

Assefa, S., and Fehrmann, H. (2004). Evaluation of Aegilops tauschii Coss. for resistance to wheat stem rust and inheritance of resistance genes in hexaploid wheat. Genet. Resour. Crop Evol. 51, 663-669. doi: 10.1023/B:GRES.0000024657. 20898.ed

Badaeva, E. D., Amosova, A. V., Muravenko, O. V., Samatadze, T. E., Chikida, N. N., Zelenin, A. V., et al. (2002). Genome differentiation in Aegilops. 3. Evolution of the D-genome cluster. Plant Syst. Evol. 231, 163-190. doi: 10.1007/ s006060200018

Badaeva, E. D., Friebe, B., and Gill, B. S. (1996). Genome differentiation in Aegilops. 2. Physical mapping of $5 \mathrm{~S}$ and $18 \mathrm{~S}-26 \mathrm{~S}$ ribosomal RNA gene families in diploid species. Genome 39, 1150-1158. doi: 10.1139/g96-145

Bedbrook, R. J., Jones, J., O’Dell, M., Thompson, R. J., and Flavell, R. B. (1980). A molecular description of telomeric heterochromatin in Secale species. Cell 19, 545-560. doi: 10.1016/0092-8674(80)90529-2

Bennett, F. G. A. (1984). Resistance to powdery mildew in wheat: a review of its use in agriculture and breeding programmes. Plant Pathol. 33, 279-300. doi: 10.1111/j.1365-3059.1984.tb01324.x

Boyko, E. V., Gill, K. S., Mickelson-Young, L., Nasuda, S., Raupp, W. J., Ziegle, J. N., et al. (1999). A high-density genetic linkage map of Aegilops tauschii,

\section{CONCLUSION}

Obtained results imply, that there is a moderate or high level of polymorphism in the genome of Ae. tauschii. We showed the similarities and differences of repetitive sequences organization are determined by geographical origin. Therefore, selected accessions of Ae. tauschii might constitute an accessible source of variation for improvement of Triticeae species like wheat and triticale.

\section{AUTHOR CONTRIBUTIONS}

MM initiated and designed the study. MK and HW initiated and designed the project. MM and JM made the mitotic chromosome preparations followed by FISH analysis. MM performed the molecular marker analysis and analyzed the data. MM wrote the paper.

\section{FUNDING}

This work was financed by the National Science Centre, Kraków, Poland (grant NCN SONATA6; 2013/11/D/NZ9/02719).

\section{ACKNOWLEDGMENT}

We would like gratefully acknowledge the technical assistance of Mrs Jolanta Belter and Mrs Joanna Maszner.

the D-genome progenitor of bread wheat. Theor. Appl. Genet. 99, 16-26. doi: $10.1007 / \mathrm{s} 001220051204$

Chen, W., Liu, T., and Gao, L. (2013). Suppression of stripe rust and leaf rust resistances in interspecific crosses of wheat. Euphytica 192, 339-346. doi: 10.1007/s10681-012-0854-2

Chennaveeraiah, M. S. (1960). Karyomorphologic and cytotaxonomic studies in Aegilops. Acta Hort. Gotoburg. 23, 85-178.

Chhuneja, P., Garg, T., Kumar, R., Kaur, S., Sharma, A., Bains, N. S., et al. (2010). Evaluation of Aegilops tauschii Coss. germplasm for agro morphological traits and genetic diversity using SSR loci. Indian J. Genet. Plant Breed. 70, 328-338.

Cowger, C., Miranda, L., Griffey, C., Hall, M., Murphy, J. P., and Maxwell, J. (2012). "Wheat powdery mildew," in Disease Resistance in Wheat, ed. I. Sharma (Oxfordshire: CAB International), 84-119. doi: 10.1079/978184593818 5.0084

Cox, T. S., Raupp, W. J., Wilson, D. L., Gill, B. S., Leath, S., Bockus, W. W., et al. (1992). Resistance to foliar diseases in a collection of T. tauschii germplasm. Plant Dis. 76, 1061-1064. doi: 10.1094/PD-76-1061

Cuadrado, A., Cardoso, M., and Jouve, N. (2008). Increasing the physical markers of wheat chromosomes using SSRs as FISH probes. Genome 51, 809-815. doi: 10.1139/G08-065

Cuadrado, A., Schwarzacher, T., and Jouve, N. (2000). Identification of different chromatin classes in wheat using in situ hybridization with simple sequence repeat oligonucleotides. Theor. Appl. Genet. 101, 711-717. doi: 10.1007/ s001220051535

Dhaliwal, H. S., Singh, H., Gupta, S., Bagga, P. S., and Gill, K. S. (1991). Evaluation of Aegilops and wild Triticum species for resistance to leaf rust (Puccinia recondita f. sp. tritici) of wheat. Int. J. Trop. Agric. 9, 118-122. 
Friebe, B., Mukai, Y., and Gill, B. S. (1992). C-banding polymorphisms in several accessions of Triticum tauschii (Aegilops squarrosa). Genome 35, 192-199. doi: 10.1139/g92-030

Gill, B. S., Browder, L. E., Hatchett, J. H., Harvey, T. L., Raupp, W. J., Sharma, H. C., et al. (1983). "Disease and insect resistance in wild wheats," in Proceedings of the International Wheat Genetics Symposium, 6th Edn, Kyoto, 785-792.

Gill, B. S., Huang, L., Kuraparthy, V., Raupp, W. J., Wilson, D. L., and Friebe, B. (2008). Alien genetic resources for wheat leaf rust resistance, cytogenetic transfer, and molecular analysis. Aust. J. Agric. Res. 59, 197-208. doi: 10.1071/ AR07315

Gill, B. S., and Kimber, G. (1974). Giemsa C-banding and the evolution of wheat. Proc. Natl. Acad. Sci. U.S.A. 71, 4086-4090. doi: 10.1073/pnas.71.10.4086

Gill, B. S., Raupp, W. J., Sharma, H. C., Browder, L. E., Hatchett, J. H., Harvey, T. L., et al. (1986). Resistance in Aegilops squarrosa to wheat leaf rust, wheat powdery mildew, greenbug, and Hessian fly. Plant Dis. 70, 553-556. doi: 10.1094/PD70-553

Guyomarc'h, H., Sourdille, P., Charmet, G., Edwards, K. J., and Bernard, M. (2002). Characterisation of polymorphic microsatellite markers from Aegilops tauschii and transferability to the D-genome of bread wheat. Theor. Appl. Genet. 104, 1164-1172. doi: 10.1007/s00122-001-0827-7

Hasterok, R., Dulawa, J., Jenkins, G., Leggett, M., and Langdon, T. (2006). Multisubstrate chromosome preparations for high throughput comparative FISH. BMC Biotechnol. 6:20. doi: 10.1186/1472-6750-6-20

Heslop-Harrison, J. S. (2000). Comparative genome organization in plants: from sequence and markers to chromatin and chromosomes. Plant Cell 12, 617-635. doi: $10.1105 /$ tpc.12.5.617

Hiebert, C. W., Thomas, J. B., Somers, D. J., McCallum, B. D., and Fox, S. L. (2007). Microsatellite mapping of adult-plant leaf rust resistance gene $\operatorname{Lr} 22 a$ in wheat. Theor. Appl. Genet. 115, 877-884. doi: 10.1007/s00122-007-0604-3

Hohmann, U., and Lagudah, E. S. (1993). C-banding polymorphism and linkage of nonhomoeologous RFLP loci in the D genome progenitor of wheat. Genome 36, 235-243. doi: 10.1139/g93-033

Huang, L., Brooks, S. A., Wanlong, L., Fellers, J. P., Trick, H. N., and Gill, B. S. (2003). Map-based cloning of leaf rust resistance gene Lr21 from the large and polyploid genome of bread wheat. Genetics 164, 655-664.

Iordansky, A. B., Zurabishvili, T. G., and Badaev, N. S. (1978). Linear differentiation of cereal chromosomes. 1. Common wheat and its supposed ancestors. Theor. Appl. Genet. 51, 145-152. doi: 10.1007/BF00273138

Jia, J., Zhao, S., Kong, X., Li, Y., Zhao, G., He, W., et al. (2013). Aegilops tauschii draft genome sequence reveals a gene repertoire for wheat adaptation. Nature 496, 91-95. doi: 10.1038/nature 12028

Kalia, B., Wilson, D. L., Bowden, R. L., Singh, R. P., and Gill, B. S. (2016). Adult plant resistance to Puccinia triticina in a geographically diverse collection of Aegilops tauschii. Genet. Resour. Crop Evol. 64, 913-926. doi: 10.1007/s10722016-0411-2

Kihara, H. (1944). Discovery of the DD-analyser, one of the ancestors of Triticum vulgare (Japanese). Agric. Hortic. 19, 13-14.

Kihara, H., Yamashita, K., and Tanaka, M. (1965). "Morphological, physiological, genetical and cytological studies in Aegilops and Triticum collected from Pakistan, Afghanistan and Iran," in Results of the Kyoto University Scientific Expedition to the Karakoram and Hindukush, ed. K. Yamashita (Kyoto: Kyoto University), 1-118.

Kolmer, J. A. (1996). Genetics of resistance to wheat leaf rust. Annu. Rev. Phytopathol. 34, 435-455. doi: 10.1146/annurev.phyto.34.1.435

Komuro, S., Endo, R., Shikata, K., and Kato, A. (2013). Genomic and chromosomal distribution patterns of various repeated DNA sequences in wheat revealed by a fluorescence in situ hybridization procedure. Genome 56, 131-137. doi: 10.1139/gen-2013-0003

Kwiatek, M., Belter, J., Majka, M., and Wiśniewska, H. (2016a). Allocation of the S-genome chromosomes of Aegilops variabilis Eig. carrying powdery mildew resistance in triticale ( $\times$ Triticosecale Wittmack). Protoplasma 253, 329-343. doi: 10.1007/s00709-015-0813-6

Kwiatek, M., Majka, M., Majka, J., Belter, J., Suchowilska, E., Wachowska, U., et al. (2016b). Intraspecific polymorphisms of cytogenetic markers mapped on chromosomes of Triticum polonicum L. PLoS ONE 11:e0158883. doi: 10.1371/ journal.pone. 0158883
Kwiatek, M., Wiśniewska, H., and Apolinarska, B. (2013). Cytogenetic analysis of Aegilops chromosomes, potentially usable in triticale ( $\times$ Triticosecale Witt.) breeding. J. Appl. Genet. 54, 147-155. doi: 10.1007/s13353-013-0133-5

Liu, S., Jackie, C., Rudd, J. C., Bai, G., Haley, S. D., Ibrahim, A. M. H., et al. (2014). Molecular markers linked to important genes in hard winter wheat. Crop Sci. 54, 1304-1321. doi: 10.2135/cropsci2013.08.0564

Luo, M. C., Deal, K. R., Akhunov, E. D., Akhunova, A. R., Anderson, O. D., Anderson, J. A., et al. (2009). Genome comparisons reveal a dominant mechanism of chromosome number reduction in grasses and accelerated genome evolution in Triticeae. Proc. Natl. Acad. Sci. U.S.A. 106, 15780-15785. doi: 10.1073/pnas.0908195106

Luo, M. C., Gu, Y. Q., You, F. M., Deal, K. R., Ma, Y., Hu, Y., et al. (2013). A 4-gigabase physical map unlocks the structure and evolution of the complex genome of Aegilops tauschii, the wheat D-genome progenitor. Proc. Natl. Acad. Sci. U.S.A. 110, 7940-7945. doi: 10.1073/pnas.1219082110

Majka, J., Majka, M., Kwiatek, M., and Wiśniewska, H. (2017). Similarities and differences in the nuclear genome organization within Pooideae species revealed by comparative genomic in situ hybridization (GISH). J. Appl. Genet. 58, 151-161. doi: 10.1007/s13353-016-0369-y

Majka, M., Kwiatek, M., Belter, J., and Wiśniewska, H. (2016). Characterization of morphology and resistance to Blumeria graminis of winter triticale monosomic addition lines with chromosome 2D of Aegilops tauschii. Plant Cell Rep. 35, 2125-2135. doi: 10.1007/s00299-016-2023-x

McFadden, E. S., and Sears, E. R. (1946). The origin of Triticum spelta and its free-threshing hexaploid relatives. J. Hered. 37, 107-116. doi: 10.1093/ oxfordjournals.jhered.a105594

Molnar, I., Kubalakova, M., Simkova, H., Farkas, A., Cseh, A., Megyeri, M., et al. (2014). Flow cytometric chromosome sorting from diploid progenitors of bread wheat, T. urartu, Ae. speltoides and Ae. tauschii. Theor. Appl. Genet. 127, 1091-1104. doi: 10.1007/s00122-014-2282-2

Naghavi, M. R., Aghaei, M. J., Taleei, A. R., Omidi, M., Mozafari, J., and Hassani, M. E. (2009). Genetic diversity of the D-genome in T. aestivum and Aegilops species using SSR markers. Genet. Resour. Crop Evol. 56, 499-506. doi: 10.1007/ s10722-008-9381-3

Ogbonnaya, F. C., Halloram, G. M., and Lagudah, E. S. (2005). "D genome of wheat-60 years on from Kihara, Sears and McFadden," in Frontiers of Wheat Bioscience, the 100th Memorial Issue of Wheat Information Service, ed. K. Tsunewaki (Yokohama: Kihara Memorial Yokohama Foundation for the Advancement of Life Sciences), 205-220.

Pedersen, C., and Langridge, P. (1997). Identification of the entire chromosome complement of bread wheat by two-colour FISH. Genome 40, 589-593. doi: $10.1139 / g 97-077$

Pestsova, E., Ganal, M. W., and Roder, M. S. (2000). Isolation and mapping of microsatellite markers specific for the D genome of bread wheat. Genome 43, 689-697. doi: 10.1139/g00-042

Roder, M. S., Korzun, V., Wendehake, K., Plaschke, J., Tixier, M.-H., Leroy, P., et al. (1998). A microsatellite map of wheat. Genetics 149, 2007-2023.

Roelfs, A. P., Singh, R. P., and Saari, E. E. (1992). Rust Diseases of Wheat: Concepts and Methods of Disease Management. Mexico: CIMMYT.

Singh, S., Chahal, G. S., Singh, P. K., and Gill, B. S. (2012). Discovery of desirable genes in the germplasm pool of Aegilops tauschii Coss. Indian J. Genet. Plant Breed. 72, 271-277.

Somers, D. J., Isaac, P., and Edwards, K. (2004). A high-density microsatellite consensus map for bread wheat (Triticum aestivum L.). Theor. Appl. Genet. 109, 1105-1114. doi: 10.1007/s00122-004-1740-7

Song, Q. J., Shi, J. R., Singh, S., Fickus, E. W., Costa, J. M., Lewis, J., et al. (2005). Development and mapping of microsatellite (SSR) markers in wheat. Theor. Appl. Genet. 110, 550-560. doi: 10.1007/s00122-004-1871-x

Sun, X., Bai, G., and Carver, B. F. (2009). Molecular markers for wheat leaf rust resistance gene Lr41. Mol. Breed. 23, 311-321. doi: 10.1007/s11032-008-9237-8

Teoh, S. B., and Hutchinson, J. (1983). Interspecific variation in C-banded chromosomes of diploid Aegilops species. Theor. Appl. Genet. 65, 31-40. doi: 10.1007/BF00276259

Thomas, J., Nilmalgoda, S., Hiebert, C., McCallum, B., Humphreys, G., and DePauw, R. (2010). Genetic markers and leaf rust resistance of the wheat gene Lr32. Crop Sci. 50, 2310-2317. doi: 10.2135/cropsci2010.02.0065 
Valkoun, J., Hammer, K., Kucerova, D., and Bartos, P. (1985). Disease resistance in the genus Aegilops L.- stem rust, leaf rust, stripe rust, and powdery mildew. Kulturpflanze 33, 133-153. doi: 10.1007/BF01997267

Wang, J., Luo, M.-C., Chen, Z., You, F. M., Wei, Y., Zheng, Y., et al. (2013). Aegilops tauschii single nucleotide polymorphisms shed light on the origins of wheat D-genome genetic diversity and pinpoint the geographic origin of hexaploid wheat. New Phytol. 198, 925-937. doi: 10.1111/nph. 12164

Wang, Y., Wang, C., Quan, W., Jia, X., Fu, Y., Zhang, H., et al. (2016). Identification and mapping of PmSE5785, a new recessive powdery mildew resistance locus, in synthetic hexaploid wheat. Euphytica 207, 619-626. doi: 10.1007/s10681-0151560-7

Wiśniewska, H., Błaszczyk, L., and Chełkowski, J. (2007). Charakterystyka genotypów pszenicy pod kątem odporności na fuzariozę kłosów, mączniaka prawdziwego i rdzê brunatną. Postêpy Nauk Rolniczych 6, 75-88.

Conflict of Interest Statement: The authors declare that the research was conducted in the absence of any commercial or financial relationships that could be construed as a potential conflict of interest.

Copyright (c) 2017 Majka, Kwiatek, Majka and Wiśniewska. This is an open-access article distributed under the terms of the Creative Commons Attribution License (CC BY). The use, distribution or reproduction in other forums is permitted, provided the original author(s) or licensor are credited and that the original publication in this journal is cited, in accordance with accepted academic practice. No use, distribution or reproduction is permitted which does not comply with these terms. 